\title{
Quality Infrastructure of Saudi Arabia and Its Importance for Vision 2030
}

\author{
V. Kumar* (1) and S. Albashrawi \\ Jubail Industrial College, Jubail Industrial City, Saudi Arabia
}

Received: 24 August 2021 / Accepted: 18 December 2021 / Published online: 23 January 2022

(C) Metrology Society of India 2022

\begin{abstract}
The quality infrastructure of the Kingdom of Saudi Arabia is discussed in this article. The effect of COVID-19 pandemic on the oil-based economy is described in detail. The goals of Vision 2030 in reference to conversion of oil-based economy of KSA to non-oil-based economy have been discussed. The quality infrastructure models for economic growth has been discussed. This article describes details of the three pillars: metrology, accreditation, and standards of economic growth in context to KSA. The role of the existing apex bodies, i.e., Saudi Standards, Metrology and Quality Organization, the National Measurement and Calibration Center, and the Saudi Accreditation Center in growth of KSA has been described. The main requirements to strengthen the QI of KSA are enhancing the apex capabilities, the setting up of new primary and secondary standards, development of strong research and development culture and awareness of quality improvement.
\end{abstract}

Keywords: Quality infrastructure; Metrology; Accreditation; Standards

\begin{tabular}{|c|c|c|c|}
\hline & IQNET & International Certification Network \\
\hline \multirow{3}{*}{$\begin{array}{l}\text { ARAC } \\
\text { AIDMO }\end{array}$} & Arab Accreditation Cooperation & CIPM & International Committee for Weights and \\
\hline & Arabic Industrial Development & & Measures \\
\hline & Mining Organization & IEC & International Electrotechnical Commission \\
\hline APAC & Asia Pacific Accreditation Cooperation & ILAC & International Laboratory Accreditation \\
\hline CMCs & Calibration and Measurement Capabilities & & Cooperation \\
\hline $\mathrm{CAB}$ & Conformity Assessment Body & ISO & International \\
\hline $\mathrm{CCU}$ & Corporate Communication Unit & & Standardization \\
\hline DU & Delivery Unit & OIML & International Organization \\
\hline GAC & GCC Accreditation Center & & Metrology \\
\hline GSO & GCC Standardization Organization & SI & International System of Units \\
\hline CGPM & General Conference on Weights and & ITU & International Telecommunication Union \\
\hline & Measures & ITC & International Trade Centre \\
\hline GEA & General Entertainment Authority & JAS-ANZ & Joint Accreditation System of Australia \\
\hline GDP & Gross Domestic Product & & and New Zealand \\
\hline GNP & Gross National Product & JCRB & Joint Committee of the \\
\hline GULFMET & Gulf Association for Metrology & & Metrology Organizations and the BIPM \\
\hline GCC & Gulf Cooperation Council & LGD & Laboratories General Department \\
\hline IIOC & Independent International Organization for & MLA & Multilateral Recognition Arrangement \\
\hline & Certification & MRA & Mutual Recognition Arrangement \\
\hline IAF & International Accreditation Forum & NATA & National Association of Testing Authority \\
\hline BIPM & $\begin{array}{l}\text { International Bureau of Weights and } \\
\text { Measures }\end{array}$ & NMCC & $\begin{array}{l}\text { National Measurement and Calibration } \\
\text { Center }\end{array}$ \\
\hline & & NMIs & National Metrology Institutes \\
\hline & & NQS & National Quality Strategy \\
\hline & & NSBs & National Standardization Bodies \\
\hline
\end{tabular}




$\begin{array}{ll}\text { PDCA/PDSA } & \text { Plan Do Check/Study Act } \\ \text { PMI } & \text { Project Management Institute } \\ \text { QI } & \text { Quality Infrastructure } \\ \text { RCAS } & \text { Regional Conformity Assessment Scheme } \\ \text { RMO } & \text { Regional Metrology Organization } \\ \text { RSO } & \text { Regional Standardization Organization } \\ \text { SAC } & \text { Saudi Accreditation Center } \\ \text { SASO } & \text { Saudi Arab Standards Organization } \\ \text { SASO } & \text { Saudi Standards, Metrology and Quality } \\ & \text { Organization } \\ \text { S \& T } & \text { Science and Technology } \\ \text { SMIIC } & \text { Standards and Metrology Institute for } \\ & \text { Islamic Countries } \\ \text { INetQI } & \text { The International Network of Quality } \\ & \text { Infrastructure } \\ \text { UN } & \text { United Nations } \\ \text { UNIDO } & \text { United Nations International Development } \\ & \text { Organization } \\ \text { UNECE } & \text { United Nations Economic Cooperation for } \\ & \text { Europe } \\ \text { WBG } & \text { World Bank Group } \\ \text { WTO } & \text { World Trade Organization }\end{array}$

\section{Introduction}

The overall growth of any nation depends upon QI. The QI of any nation is consisting of internationally recognized metrology, standards, accreditation, conformity assessment, and market surveillance. The QI is built on a technological pyramid to ensure traceability of the accurate and precise measurements to the International System of Units. It is a basic empowering system for providing testing, calibration, inspection, and certification. The QI is a hidden power that connects the University, Research and Development Laboratories, Science and Technology Organizations, Civil Societies, Enterprises, and Government. The economic growth and quality of life of any nation depend upon these units.

As per the world competitiveness ranking 2021, gross domestic product of KSA is USD 700.1 Billion having 20th rank [1] in the world. The real GDP growth for the year 2020 was $-4.1 \%$ on 29 rank. The economy of KSA is almost oil-based. The average crude oil production of KSA from January 2002 to May 2021, with 233 observations, was 9.423 million Barrel/Day. Before the COVID-19 pandemic, the oil production of the KSA was at an all-time high in April 2020 (11.642 million Barrel/Day) and lowest in February 2002 (7.121 million Barrel/Day) [2].
The oil prices are very volatile; in 2012, the price of 1 barrel of crude oil was nearly 120 USD; in 2016, it dropped to 40 USD; and in 2020 it was 20 USD, which badly affects the economy [3]. KSA possesses $266,578,000,000$ barrels of confirmed oil reserves as on 2016, 2nd rank in the world and it is about $16.2 \%$ of the world's total oil reserves of $1,650,585,140,000$ barrels. At the current oil consumption rate, excluding unconfirmed reserves, and without net exports the KSA oil reserve will be available about up to 221 years. Unfortunately, in the March 2020 almost all nations begun affected by the COVID-19 pandemic. This has affected the world activities of the economy and therefore slowed down the economic growth and loss of employment, etc., and created a challenge to restore the economy. Due to this pandemic, the crude oil export of KSA decreased to 5 million barrels/day in June 2020 in comparison with April 2020 in which it was more than 10 million barrels/day [4]. Presently, KSA is in transition mode to shift from an oil-based economy to a non-oilbased economy by 2030 (Vision 2030) to stabilize the economy. In the context of shifting to a non-oil-based economy, 40 industrial cities were established in different areas of KSA. The quality of KSA infrastructure is ranked 37 out of 148 as per International Trade Center [5].

The Vision 2030 [6] is specifically designed around three ideas: a vibrant society, a thriving economy, and an ambitious nation. The 1st idea, vibrant society is crucial to accomplish the goals of Vision 2030 and a strong base for economic fortune. The KSA understands the value of a vibrant society. Members of this society are living happily with a decent life in a beautiful atmosphere supported by an empowering social and healthcare system. They feel gratified of their national identity and their ancient cultural heritage. In the 2nd idea, a thriving economy makes chances to grow all by developing an education system endorsed to the market requirements and generating economic opportunities for small, medium, and large entrepreneurs. In the 3rd idea, KSA will identify encouraging economic sectors to investment implements, diversify their economy, and create job opportunities. The main goals of Vision 2030 are to lower the unemployment rate from 11.6 to $7 \%$, raise the share of non-oil exports from 16 to $50 \%$, and elevate the KSA ranking index from the current position of 37 to be among the top five nations on the E-Government Survey.

An executive opinion survey [7] was performed on various indicators mentioned in Fig. 1. From a list of 15 indicators, respondents of this survey were asked to select 5 indicators that they recognized as the important attraction factors of their economy. The percentage of responses per the indicator is shown in Fig. 1,

It is obvious that the reliable infrastructure indicator has the highest percentage of response. QI plays a very crucial 
role for the growth of a nation. The QI is the foundation for getting excellent and continuous development targets stated by UN to guarantee the inclusive economy improvement, well-respected life of people and also earth safety. The International Network of Quality Infrastructure-a group of fourteen international organizations [8]-promotes the significance of QI and its efficient global implementation, particularly in developing nations with ensured metrological traceability to SI units. These fourteen international organizations are the International Bureau of Weights and Measures, International Accreditation Forum, International Electrotechnical Commission, Independent International Organization for Certification, International Laboratory Accreditation Forum, International Certification Network, International Organization for Standardization, International Trade Center, International Telecommunication Union, International Organization of Legal Metrology, United Nations Economic Cooperation for Europe, World Bank Group, World Trade Organization and United Nations International Development Organization.

\section{The Economic Growth and Quality Infrastructure Models}

Economic growth is not just measured by the increase in the capacity of production of one's economy but also includes an improvement in the condition of life of the people. The economic growth can be calculated through the percentage variations of many indicators like GDP, Gross National Product and GDP per capita, etc. The QI is important to the productivity and growth of manufacturing industries to enhance innovation, reduce economic distances, enable the international markets access, reduce cost amount, and increase the revenues. QI of India and its importance for inclusive national growth has been studied [9].

UNIDO defines [10] the QI as: "the system comprising the organizations (public and private) together with the policies, relevant legal and regulatory framework, and practices needed to support and enhance the quality, safety and environmental soundness of goods, services, and processes. The quality infrastructure is required for the effective operation of domestic markets, and its international recognition is important to enable access to foreign markets. It is a critical element in promoting and sustaining economic development, as well as environmental and social well-being. It relies on metrology, standardization, accreditation, conformity assessment, and market surveillance."

The neoclassical model (Solow-Swan) of economic growth is a well-known model. The growth model of Harrod-Domar (1946) was modified by adding the increase in productivity to develop the Solow-Swan model. In this new model, more weight is given to the new capital than

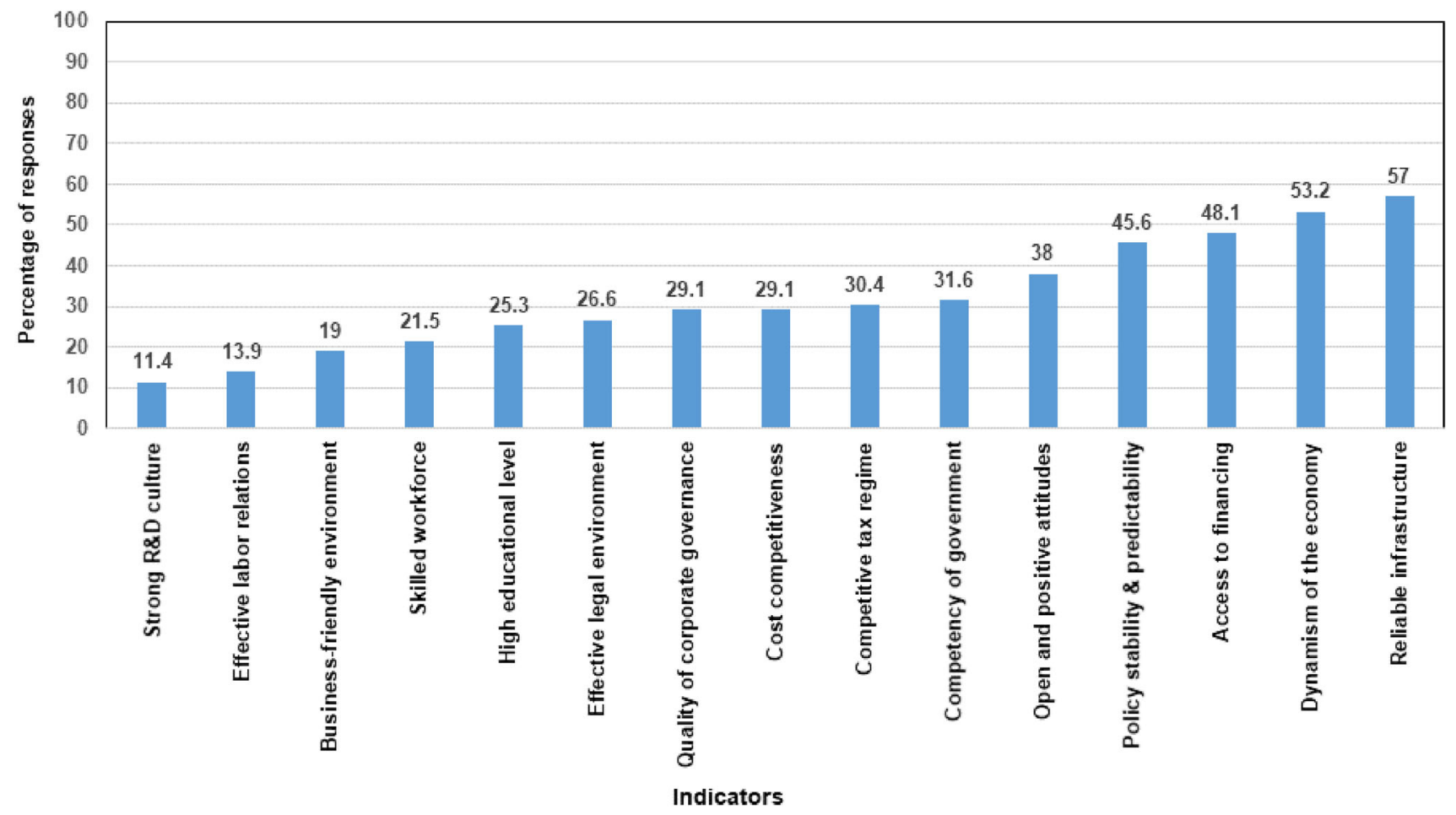

Fig. 1 Executive opinion survey of various indicators 
the old one. This model [11] demonstrates the effect of technological progress, rate of population growth, and economic growth on the economy for a certain period. The quadruple helix model given by Carayannis and Campbell [12] is widely used for economic improvement through the interaction between different entities. 'Mode 3' ("system consisting of 'Innovation Networks' and 'knowledge Clusters' for knowledge creation, diffusion and use") agrees and highlights the co-existence and co-evolution of various knowledge and invention concepts. The 'triple helix' model [13] stresses three 'helices' academia/universities, industry, and state/government intermingle to each other to create a general improvement structure. 'Quadruple helix' model was developed by adding 'fourth helix" "media-based and culture-based public" in the triple helix model. The strong relations between the four helices of this model are enabled via an unseen strong QI. The QI makes sure conformity assessment through well-recognized metrological, accreditation, and standards institutions. The QI in developed nations (e.g., USA) is well formed and, therefore, results in their high GDP.

\section{Quality Infrastructure in the Kingdom of Saudi Arabia}

The potency of the national QI system mostly depends upon the overall measurable capabilities of international equivalence available with apex QI institutions and the propagation mechanism of the available QI facilities to all the stakeholders across the country. The summary of international and KSA's QI organizations is shown in Fig. 2. All the components of QI have been appropriately established in the KSA results in constructing an internationally recognized QI.

\subsection{Metrology}

A national metrology system depends on reliable and highly accurate measurement standards. The purpose of appropriate metrology infrastructure is to assure the validity of measurements, reliability of the inspection and test results, and head to mutual international recognition. A reliable national metrology system can guarantee the receipt of proper quantities to protect traders and consumers, general protection of the national economy, and can contribute to eliminating the technical obstacles for smooth global trade. It can keep the healthiness and security of humanity resulted in prosperity and standard of living. The metrology infrastructure helps to measure environmental parameters and their variations and outline their future effects on living beings. In a landmark decision, United Arab Emirates and Saudi Arabia, the BIPM's member states voted on November 16, 2018, to revise the SI Units [14]. It was decided in the 26th meeting of the General Conference on Weights and Measures in Versailles, France, that all SI units will now be defined in terms of natural physical constant (speed of light, hyperfine structure transition frequency of the Cesium-133 atom $\mathrm{s}$ luminous efficacy, Planck constant, the elementary electric charge, the Boltzmann constant, and Avogadro constant). This will guarantee the constancy of the SI units in the future.

\subsubsection{Gulf Association for Metrology}

The Gulf Cooperation Council Standardization Organization supported the establishment of a Regional Metrology Organization known as the Gulf Association for Metrology [15]. The GULFMET is established to bring together National Metrology Institutes of the Gulf Cooperation Council participant countries (United Arab Emirates, Kingdom of Bahrain, Kingdom of Saudi Arabia, Sultanate of Oman, State of Qatar, State of Kuwait and the Republic of Yemen) and internationally recognized by the International Committee for Weights and Measures. GULFMET is an excellent platform to help communicate, develop nourishment through the exchange of knowledge and cooperation among the member States, and enrich metrological capabilities. The GULFMET is responsible for carrying out all the required activities to fulfill the requirements of international recognition. It also contributes to the metrological infrastructure required to protect consumers, health, safety, and the environment. The GULFMET supports building up a strong metrological infrastructure to improve the quality and encourage trade among its member states and the other countries of the world. It enhances cooperation with the BIPM and OIML. The CIPM granted provisional acceptance of GULFMET as an RMO in accordance with the procedures of the Joint Committee of the Regional Metrology Organizations and the BIPM.

\subsubsection{Saudi Standards, Metrology and Quality Organization}

Saudi Arab Standards Organization was established in 1972, and in February 2009, its name [16] was changed to Saudi Standards, Metrology, and Quality Organization. SASO's responsibilities are to introduce and execute quality initiatives to the Kingdom. The SASO is a technical government body in KSA that governs tasks related to standards, metrology, and quality. SASO places down Saudi standards in all required fields such as goods, products and services, and measurement and establishes procedures of conformity evaluation and certification. It offers 
Fig. 2 Components of international QI and corresponding QI of KSA

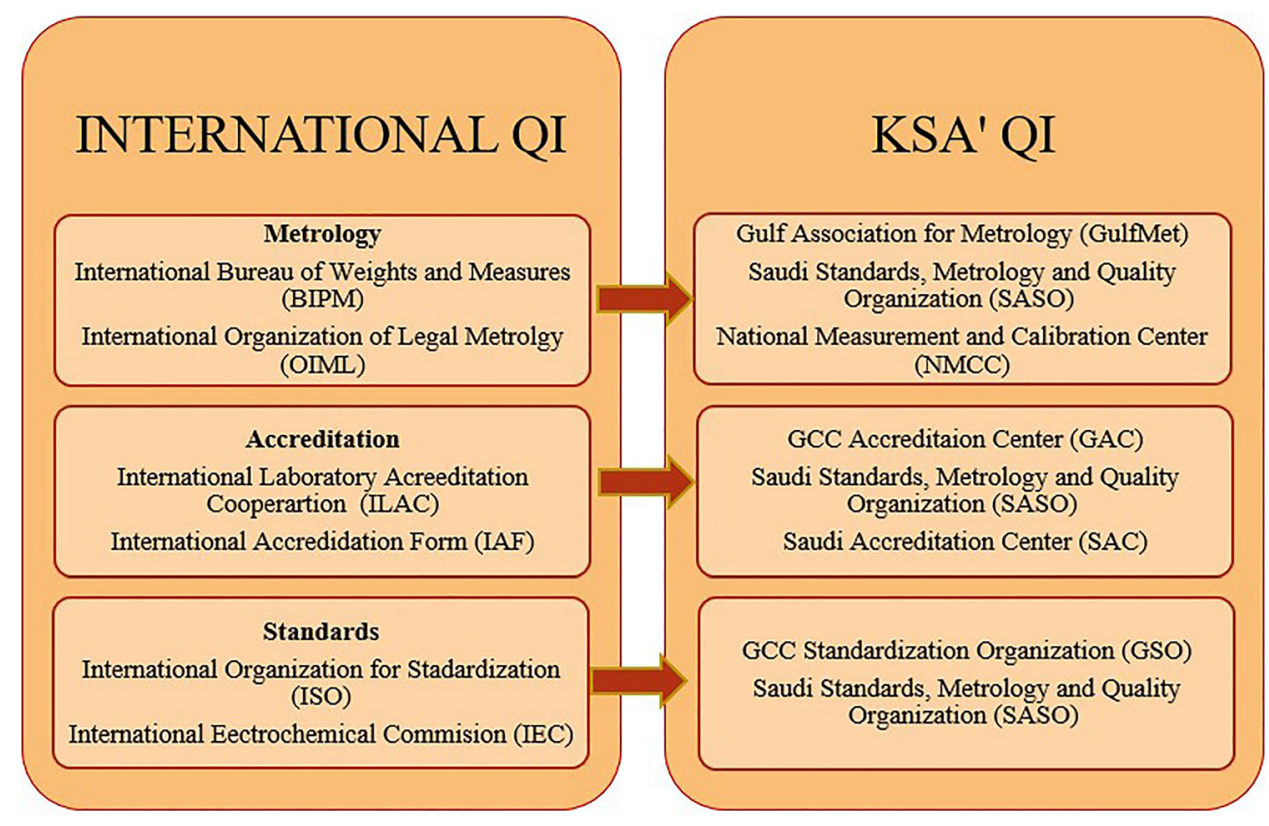

administering changes. In this model, improvement actions are tested on a small scale before updating procedures and working practices.

\subsubsection{SASO Initiatives in the Field of the NQS}

NQS is the general framework in accordance with Kingdom's Vision 2030 and wide-ranging perception of quality and institutional excellence in various sectors of KSA [21]. The objective behind building the NQS is to raise the level of quality of national products and services, enhance its competitiveness in global market, to grow all business sectors in a rationed and precise manner, with better value addition, and their positive impact on GDP and GNP. The NQS has been developed to achieve the government's orientation toward expanding the provision of services to citizens in all parts of the KSA, to facilitate them in obtaining the services they seek and to emphasize their national role. To achieving the objectives of the NQS, SASO initiated the establishing local and international partnerships with associations, institutes, and scientific and professional research centers in the field of quality and institutional excellence. SASO framed Saudi standards in many fields, e.g., construction and building materials, chemical and petroleum products, electrical and electronic products, mechanical and metal products, textile products, weights and measures, quality control and conformity, information and documentation, and services.

To ensure the quality of the products, some initiatives taken by SASO are: del. "PDCA cycle is a continuous loop of planning, doing, checking (or studying), and acting". It gives an easy and efficient methodology for solving difficulties and 
1-Saudi Program for product safety (Saleem) which is responsible for the safety of the product and ensure that they are not defected [22].

2-The national program for legal calibration (Taqees) is responsible for unifying the legal tests of measurements based on the international standard [22]. Also, it is worth mentioning that SASO has approved 30,389 standard items [22] and it got membership in 293 international committees [22] since its establishment.

On 16 June 2021, Austrian Standards International and the Saudi Standards, Metrology and Quality Organization signed a cooperation Program in a virtual ceremony. Its objective: intensifying the exchange of knowledge and experiences in the fields of Standardization to support trade relations between the two countries [23].

\subsubsection{Metrological Capabilities in the Kingdom of Saudi Arabia}

At the end of the last century and the beginning of the international industrial revolution, the need for harmonizing measurement standards around the world for an agreed system of Units has arisen. In 1875, the Meter convention was signed in Paris, which was the beginning of harmonizing the international measurement standards and establishing the scientific basis of the SI. Consequently, an NMI was decided in each country to establish its national measurement standards and harmonies with standards of the other countries' signatories to the meter convention. Harmonization of the measurement standards covers the realizations of the 7 basic units and the 22 derived units. SASO has Mass, Density, Force, Volume, Hardness, Viscosity, Pressure, Gravity, Torque, Time and Frequency, acoustic, RF and Microwave, Vibration, Voltage, Power and energy, Impedance, Electromagnetic, Contact Temperature, Humidity, Thermal Radiation, Wavelength, Gauge Bock, Surface, Dimensions, Gas, Organic, Electrochemistry measurement laboratories. Calibration Support and Quality Department of SASO links NMCC and the customers. [24]

\subsubsection{National Measurement and Calibration Center}

In KSA, the NMCC was established in $1406 \mathrm{AH}$ (1986 AD). The main responsibilities of NMCC [25] are maintaining and developing the national measurement standards, calibrating the measuring instruments and standards, researching in metrology, and participating in key and supplementary comparison programs regionally and internationally. It provides contributions to serve the scientific, legal, and industrial metrology in the governmental and private sectors. It also ensures metrological traceability of the measurement results to the SI units. The NMCC is structured in 8 departments and includes 30 specialized national laboratories serving scientific, legal, and industrial metrology in the governmental and private sectors. The organization chart of NMCC is shown in Fig. 3.

NMCC is equipped with advanced measurement standards and calibration systems on the primary and secondary levels. In addition, NMCC provides technical consultations in establishing and developing calibration laboratories, designing and functioning calibration systems in cooperation with industrial companies. These consultations are served to accredited laboratories and industrial bodies upon their request to enhance their production efficiency and improve their competitiveness in the international markets. Also, NMCC contributes to environmental protection, health, and safety and provides training services. The training aims to enhance the level of the technical staff in industry and services sectors to perform accurate calibration, testing and to prepare calibration certificates and test reports following the requirements of ISO/IEC 17025 including correct figures of uncertainty in measurement results.

The NMCC participated in 12 International comparisons. Detail is shown in Fig. 4

\subsubsection{Laboratories General Department}

Laboratories General Department of SASO consists of laboratories of Textile products, Construction and building material, Electrical products, Petroleum products, Mechanical and metallic products, and chemicals. Also, it consists of the Organization Unit of technical proficiency Testing and Vehicles inspection unit. In some tests, Saudi standards laboratories accredited corresponding to the international standard (ISO 17025/2005), which provides international recognition for laboratories' test results. SASO's laboratories were established in Riyadh, and also, its branches in Makkah Al-Mukarramah and the Eastern Province. These laboratories have been leveraged with many new latest devices and instruments in various fields [26]. The LGD conducts studies and research to develop Saudi standards, reviews and provides technical comments on Saudi standard projects, gives technical consultations in the field of testing to various departments of SASO and outside organizations, and carrying out sample' tests.

\subsection{Accreditation}

Accreditation is an assessment process that is designed to determine whether a conformity assessment body is capable of performing its conformity assessment activities. The accreditation activities may include calibration, testing, inspection, or certification. 


\section{NMCC Organization Chart}

\section{NMCC is structured of 8 Departments and 30 Laboratories}

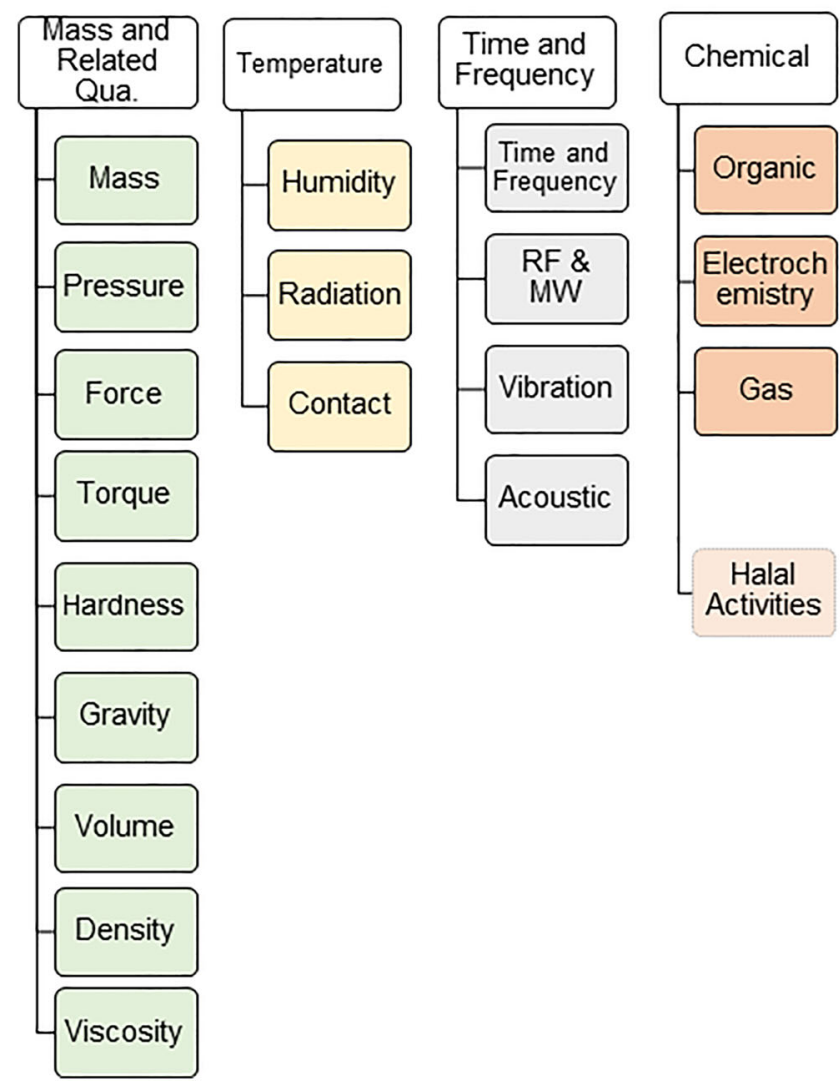

Fig. 3 The Organization chart of NMCC [25]

NMCC has participated in 12 international comparisons

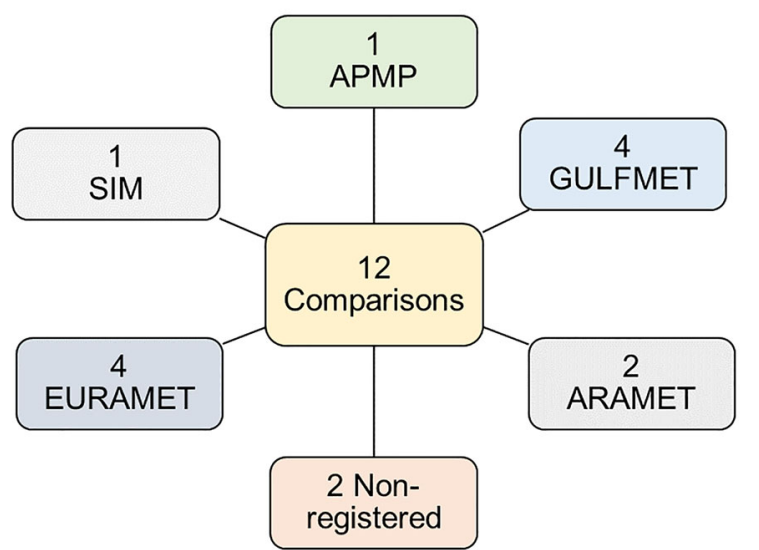

Fig. 4 International Comparisons [25]

\subsubsection{GCC Accreditation Center}

The Governments of GCC approved the establishment of the GCC Accreditation Center [27], to deliver reliable

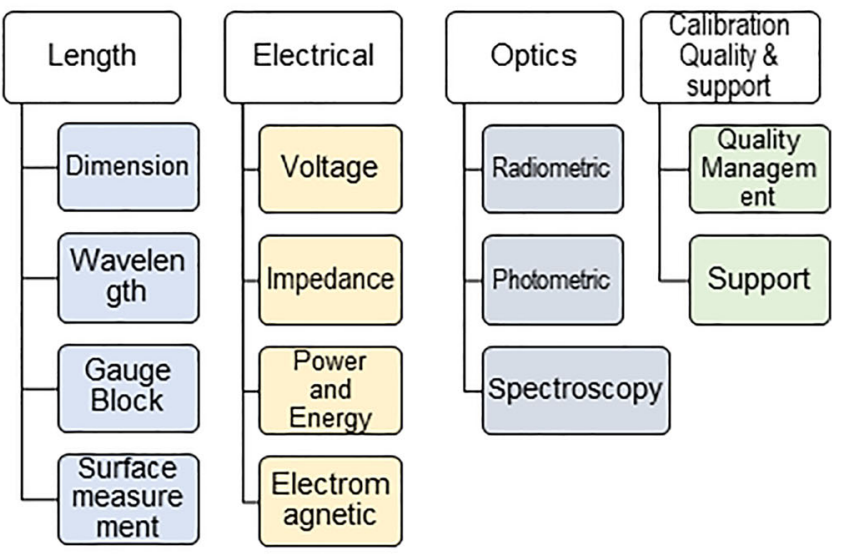

services to $\mathrm{CABs}$, inspection bodies, and certification bodies in all member states. The establishment of the GAC had been founded after the study made by the Organization of Joint Accreditation System of Australia and New Zealand which was provided by the Australian National Association of Testing Authority during the period from 2005 to 2010 . The GAC was able to set the documents, procedures and provide training for the experts, support to the committees and task forces at the gulf area to work and follow up with different projects and to review the three phases of the outputs of the technical consultations.

GAC timely plans and conducts due assessments for the CABs to verify its competence, informs accredited CABs about the modifications in the accreditation needs and gives information about appropriate methods to obtain tractability of measurement results. GAC publicly announces the current status of the accreditation granted to $\mathrm{CABs}$ and updates regularly in line with ISO/IEC 17011 requirements. 


\subsubsection{GAC Recognition at the International Level}

At the international level, accreditation is monitored by ILAC and the IAF. The decisions of these organizations determine the nature of the accreditation offered by the GAC and its equivalent bodies in other countries. Good participation of the GCC is required to be recognized by these organizations. GAC participates in the operations of ILAC and IAF. GAC is also working at the provincial level and is a member of both the Arab Accreditation Cooperation and the Asia Pacific Accreditation Cooperation. GAC is a signatory to the ARAC Multilateral Recognition Arrangement and ARAC Mutual Recognition Arrangement recognition agreements, which are recognized at the international level by ILAC and IAF. This implies that a test report or certificate accredited by GAC is also recognized by the signatories to the ILAC MRA. In this way, the GAC accreditation acts as an international passport to trade. GAC is a signatory to the Testing laboratories, Calibration Laboratories, and Inspection Bodies. [28]

\subsubsection{The Saudi Accreditation Center}

The SAC [29] is the national authority to provide accreditation services for conformity assessment bodies in KSA. It includes testing and calibration laboratories in all fields (e.g., electrical, construction and building materials, chemical, measurement and calibration, etc.), Inspection bodies, Certification bodies, and Halal bodies. Participating in the development of the national economy by raising the level of the technical competency of national CABs and ensuring better consumer protection is the mission of SAC.

In 2011, Saudi Arabia has signed the international accreditation agreement by which Saudi standards were accredited in many fields [22]. The quality system in the laboratories of the national center is based on the international standard requirements (ISO/IEC 17025, ISO 17034, and ISO 17043). In the period December 2019-January 2020, the quality system was evaluated (Peer review) in 11 field with coordination of GULFMET in which the system was accredited and certified as per the requirements of (ISO/IEC 17025). The SASO performed 285 accredited tests [22].

\subsubsection{International Inter-comparison of SASO and BIPM}

The CIPM MRA is the framework that validates the international equivalence of measurement standards of NMI and their calibration and measurement certificates. The SASO participated in 44 international inter-comparisons with BIPM in different metrology areas [30]. The international inter-comparisons between SASO and BIPM are mentioned in Table 1.
Standards help in numerous economic and social activities to improve the cost-effective distribution of resources. Standards not only help the industry to increase its profit at the same time assure high-quality goods and services for users at a lower price. Therefore, the implementation of standards increases economic efficiency. Standards play an important role in the research and innovation development with their different feedback loops as shown in Fig. 5 [31].

GCC Supreme Council established GSO, a Regional Standardization Organization in December 2001, and started its operation in May 2004. Its headquarter is in Riyadh, KSA [33]. GSO operates as a single regulatory system to control the quality of products in the GCC market. The main objectives of GSO are to assist GCC to accomplish its aims and unification of the standardization activities and ensure their implementation and compliance. Also, other objectives are to advance the manufacture and service sectors, nurture the trade among GCC member states, protect the customer, environment, and public health, boost the economy of GCC participating countries and meet the requirements of Gulf Custom Union and Gulf Common Market.

GSO develops and defines GSO Standards following specific requirements that have been recognized by National Standardization Bodies, businesses, and other users of standards. GSO standards are developed by technical teams of experts in that field/sector. The members of these Technical Committees are selected by the NSBs. Each NSB member in GSO is grateful to adopt each GSO Standard as a national standard and ensure its availability to the customers. Therefore, one GSO Standard turns out to be the national standard in all GCC countries. Moreover, at least $80 \%$ of adopted GSO Standards are identical to International Standards.

\subsubsection{The GSO Quality Infrastructure Framework}

The GSO was involved in the following activity for improving the quality infrastructure of GCC member states

Table 1 Comparison of SASO and BIPM

\begin{tabular}{lll}
\hline S. No. & Metrology Area & Number \\
\hline 1 & Acoustics, Ultrasound, Vibration & 2 \\
2 & Electricity and Magnetism & 14 \\
3 & Length & 7 \\
4 & Mass and related quantities & 11 \\
5 & Photometry and Radiometry & 2 \\
6 & Thermometry & 3 \\
7 & Time and Frequency & 3 \\
8 & Chemistry and Biology & 2 \\
\hline
\end{tabular}




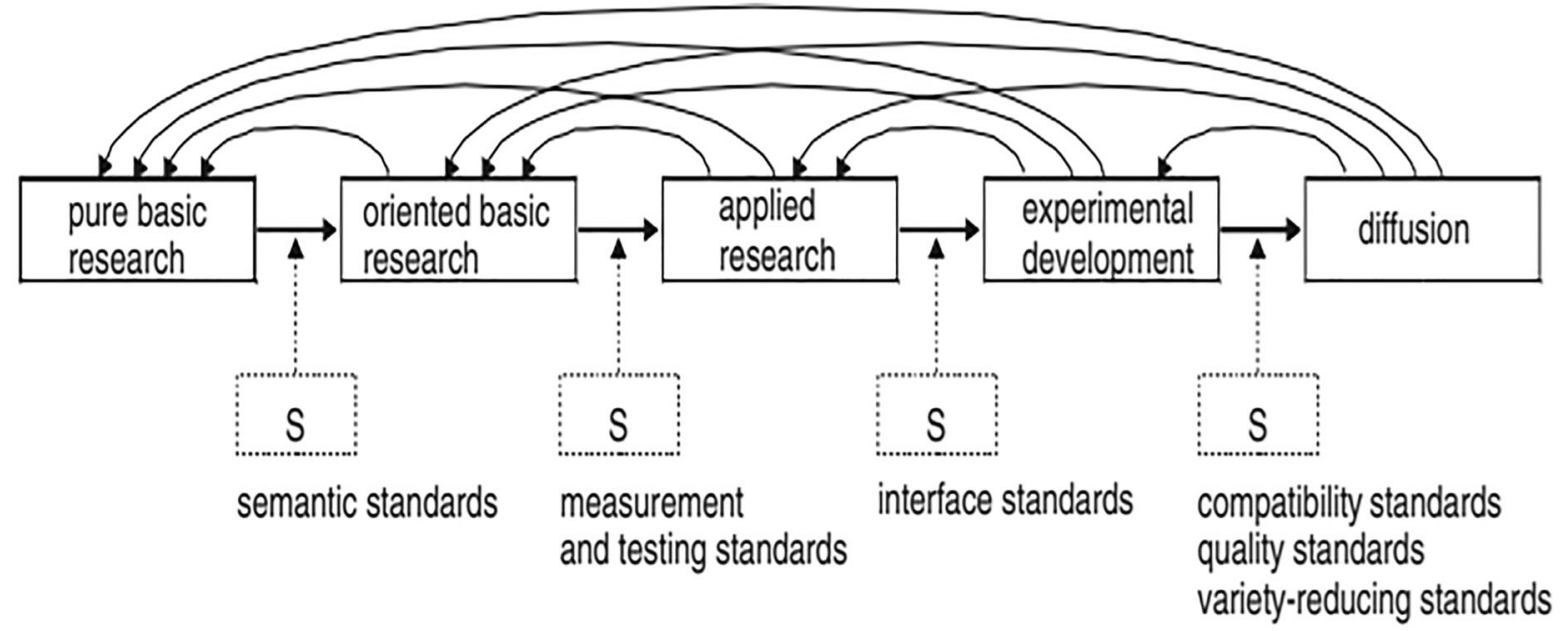

\section{Function Reduction of information cost of Standards Reduction of transaction cost}

\author{
Interoperability between Increased quality \\ components \\ Reduced health, safety, privacy risks \\ Building critical mass \\ Savings in adaption cost Economies of scale \\ Creation of network externalities \\ Interoperability between products
}

Fig. 5 Standards role in Research and innovation [32]

- GSO has issued more than 23,524 Unified Gulf Standards and Technical Regulations so far covering most of GCC sectors.

- GSO developed the GCC Conformity Assessment Scheme in keeping in attention of reducing the technical obstacles of trade and smoothing the free movement of supplies across borders within the GCC member states and the rest of the world.

- More than 440,000 Conformity Certificates for Vehicle, tiers, Motorcycle have been issued

- GSO approved 69 Notified Bodies in many countries around the world. 35,608 products had the G-Mark through more than 37,419 Conformity Certificates issued through the GCC Conformity Tracking System.

- GSO established the GAC

- GSO has created and hosted the GULFMET as a RMO.

- GSO invests in strengthening the knowledge, skills, and know-how of its members through extensive training and technical assistance programs in the field of standardization and its related activities. GSO established the GCC Standardization Training Center; till now, GSO has trained and qualified more than 14,000 participants through 500 training courses.

At the regional and international, GSO has an observer membership in ISO, IEC, WTO, Codex, Standards and Metrology Institute for Islamic Countries, Arabic Industrial
Development and Mining Organization, etc. GSO continues its close international cooperation with its partners around the world through $62 \mathrm{MoUs}$ and cooperation agreements with 50 national, regional, and standardization organizations.

\subsection{Conformity}

GSO took a huge forward jump by implementing the Regional Conformity Assessment Scheme project in November 2005. This giant step by GSO aims to progress the GCC objectives through the coordination, integration, and construction of the standardization zones and QI in the member states. The project has been intended to focus on the present procedures and practices to verify the conformity of trade of the locally produced product. The outcome of this project was to develop a harmonized unified regional system for developing the schemes. The target of the system is to serve the national and regional interests of GCC member states and streamline commercial activities.

\section{Concluding Remarks}

This article pointed out that a strong QI is crucial for fulfilling Vision 2030 and switching to a non-oil-based 
economy. To strengthening QI of the KSA, it would require to consider some recommendations such as enhancing the apex capabilities by SASO and implementing new standard in the system. Also, the calibration and measurement capabilities of SASO are required to be extended in the areas of energy, environment monitoring, biomedical, and quantum standards. In addition, the setting of new primary/national standards should be considered and a better synergy among three pillars (metrology, standards, and accreditation) of QI must be initiated. Furthermore, establishment of strong collaboration between four helices (government, university, S\&T institutions, civil society \& media, and enterprises) strengthens the legal framework, and legal metrology to be adopted intensively. Development of strong research and development culture are required to be implemented, and more research centers must be established. Also, it is very important to improve competitiveness across priority sectors, the industrial standard enforcement mechanism and motivate private sectors to participate in public infrastructure projects. Awareness of the quality improvement should be increased.

Acknowledgements We would like to thank Dr. Sanjay Yadav, Chief Scientist, CSIR-National Physical Laboratory, for his valuable guidance and support.

\section{References}

1. https://www.imd.org/.

2. https://www.ceicdata.com/en/indicator/saudi-arabia/crude-oilproduction.

3. https://www.macrotrends.net/1369/crude-oil-price-history-chart.

4. https://www.worldometers.info/oil/saudi-arabia-oil/.

5. https://www.intracen.org/layouts/CountryTemplate.aspx?pageid=4 $7244645034 \& \mathrm{id}=47244646364$.

6. https://www.vision2030.gov.sa/.

7. https://www.imd.org/globalassets/wcc/docs/wco/pdfs/countrieslanding-page/sa.pdf.

8. https://www.inetqi.net/.

9. D.K. Aswal, Quality infrastructure of India and its importance for inclusive national growth, MAPAN-J. Metrol. Soc India, 35 (2020) 139-150.
10. Quality infrastructure- building trust for trade, The United Nations Industrial Development Organization, 2016, Retrieved from https://www.unido.org/sites/default/files/2016-05/UNIDO_ Quality_system_0.pdf.

11. N. Moroianu and D. Moroianu, Models of the economic growth and their relevance, Theor. Appl. Econ., XIX (2012) 135-142.

12. E.G. Carayannis and D.F. Campbell, "Mode 3' and 'Quadruple Helix': toward a 21st century fractal innovation ecosystem', Int. J. Technol. Manag., 46 (2009) 201-234.

13. H. Etzkowitz and L. Leydesdorff, The dynamics of innovation: from national systems and 'mode 2' to a triple helix of universityindustry-government relations, Res Policy, 29 (2000) 109-123.

14. https://www.gso.org.sa/en/metrology/.

15. https://www.gso.org.sa/en/metrology/gulfmet/.

16. https://saso.gov.sa/en/pages/default.aspx.

17. https://www.iso.org/member/1516.html.

18. https://www.pmi.org/membership/chapters/europe-middle-eastafrica/saudi-arabia/kingdom-of-saudi-arabia-chapter/.

19. https://www.pmi.org/.

20. https://www.mindtools.com/pages/article/newPPM_89.htm.

21. https://www.saso.gov.sa/en/sectors/NQS/Pages/NQS.aspx.

22. SASO Annual Report 2020.

23. https://saso.gov.sa/en/mediacenter/news/Pages/saso_news_1215. aspx.

24. https://www.saso.gov.sa/en/sectors/measurement/Pages/about.aspx.

25. https://www.smiic.org/mysql/upload/files/202002/5e3a8719d0adb1580893977.pdf.

26. https://www.saso.gov.sa/en/sectors/laboratories/Pages/about.aspx.

27. https://www.gac.org.sa/en.

28. https://ilac.org/signatory-detail/?id=103.

29. https://saac.gov.sa/en/.

30. https://www.bipm.org/kcdb/comparison/advanced-search?display AdvancedResult $=$ true $\% 20 \&$ tab $=2 \&$ keywords $=\&$ areaId $=-1 \&$ subfieldId $=-1 \&$ comparisonType $=-1 \% 20 \&$ organizationId $=-1 \% 20 \&$ $\%$ 20 countries $=1 \&$ countries $=151 \&$ progressStatus $=-1 \% 20 \&$ startYear $=\&$ endYear $=\&$ validity $=-1$.

31. The law, economics and politics of International Standardisation, Edited by Panagiotis Delimatsis, Cambridge University Press, (2015).

32. K. Blind and S. Gaugh, Research and standardisation in nanotechnology: evidence from Germany, J. Technol. Transf., 34 (2008) 320-342.

33. https://www.gso.org.sa/en/about-gso/.

Publisher's Note Springer Nature remains neutral with regard to jurisdictional claims in published maps and institutional affiliations. 